\title{
Relationships Between the Home Learning Environment, Weight Status, and Dietary Intake: Results From a Cross-Sectional Study of Preschool-Aged Children in New South Wales, Australia
}

\author{
Megan L. Hammersley ${ }^{1}$ D $\cdot$ Rachel A Jones $^{1} \cdot$ Anthony D Okely $^{1}$
}

Accepted: 25 February 2021 / Published online: 20 March 2021

(c) The Author(s), under exclusive licence to Springer Science+Business Media, LLC, part of Springer Nature 2021

\begin{abstract}
The home learning environment is a potential correlate of childhood obesity and obesity-related factors. We examined relationships between the home learning environment and weight status and the home learning environment and dietary intake, in a sample of 303 preschool-aged children from Australia. We measured their height and weight, and their parents completed a questionnaire that included questions related to demographics, dietary intake, and the home learning environment. Parents reported their children's usual consumption of foods from each food group, the frequency of their discretionary food intake, and the frequency of home activities that might support cognitive stimulation. We analysed relationships using regression, adjusting for parents' education level, and household income. We found no significant associations between the home learning environment and BMI or weight category. We found a significant inverse relationship between the overall home learning environment and discretionary food intake scores, but when stratified by income, this result was significant for children from lower-income families only. Regarding specific elements of the home learning environment, we found significant inverse relationships between discretionary food intake and both reading to children, and teaching them the alphabet. While reading was significant across all income levels, teaching the alphabet was only significant in children from higher-income families. We also found significant inverse relationships between discretionary food intake and: visiting a library, teaching numbers or counting, and teaching songs, poems and nursery rhymes in lower-income families only. There was no association between the home learning environment and meeting individual dietary guidelines. This area requires further research to explore broader home environment factors that may influence these relationships. We also suggest that interventions explore the use of strategies to improve the home learning environment to determine its efficacy in improving healthy eating behaviors.
\end{abstract}

Extended author information available on the last page of the article 
Keywords Home learning environment · Cognitive stimulation · Early childhood development $\cdot$ Overweight $\cdot$ Obesity $\cdot$ Dietary intake

\section{Introduction}

The World Health Organization (2012) has described childhood obesity as one of the most serious health challenges facing the world today, increasing the risk of development of chronic diseases in later life ( $\mathrm{Ng}$ et al., 2014). Childhood obesity can result from an imbalance of food intake and physical activity and the underlying causes of this imbalance are multifactorial. Environmental, genetic, behavioral, physiological, and social influences all play a role in the development of childhood obesity (National Health \& Medical Research Council, 2013a). Children often establish unhealthy behaviors, such as consumption of energy-dense foods and beverages, lower physical activity, and increased sedentary behavior early in childhood (Yavuz et al., 2015), and parental influence is a key determinant in the shaping of many of these behaviors (Natale et al., 2014; Niemeier, Hekner, \& Enger, 2012).

The home environment is an important factor influencing the development of overweight status and obesity in children. This appears to be due to the effect of diverse and complex elements, such as the availability of healthy foods (Rosenkranz \& Dzewaltowski, 2008; Vereecken et al., 2010), the availability of physical activity resources (Lau et al., 2015), parenting style (Johnson et al., 2012; Sokol et al., 2017), family psychosocial dysfunction (Christoffel \& Forsyth, 1989), stress (Garasky et al., 2009), lack of warmth and limit setting (Avula et al., 2011), neglect, and poor living standards (Lissau-Lund-Sorensen \& Sorensen, 1994; Lissau \& Sorensen, 1992). Previous studies have reported a direct relationship between a positive home learning environment (HLE)/cognitive stimulation and the following: lower rates of overweight/obesity (Garasky et al., 2009); lower weight gain over time (Avula et al., 2011; Strauss \& Knight, 1999); and healthy eating behaviors (den Bosch \& Duch, 2017; Pieper \& Whaley, 2011). However, not all studies that have explored the HLE and overweight/obesity have found a relationship between the two (den Bosch et al., 2017), and one study found that this relationship differed according to sex and household income (Avula et al., 2011). Although there is seemingly a lack of consistent results across studies, it is apparent that parenting and home dynamic characteristics play a critical role in the development of positive health and lifestyle outcomes. While studies have been conducted in a variety of populations and age groups, only three studies to date have been carried out at the preschool age (den Bosch et al., 2017; Pieper et al., 2011; Strauss et al., 1999) and only one study has explored relationships between the HLE and both overweight/obesity and eating behaviors in this age group (den Bosch et al., 2017). Therefore there is a critical need for further research to expand this evidence base and better inform potential interventions.

The purpose of our paper was to build on previous work and examine the relationship between HLE and weight status, and HLE and dietary intake, in a sample of preschool-aged children from New South Wales, Australia. We hypothesised that engagement in intellectually stimulating activities in the home environment (as 
measured by an aggregate HLE index) would be inversely associated with BMI and overweight/obesity classification, positively associated with healthy eating behaviors, and inversely associated with frequency of consumption of energy-dense discretionary foods, even after adjusting for potentially key confounders such as parental education and income.

\section{Methods}

The Early Start Baseline Project was a cross-sectional study conducted with parent and child (aged 3-5 years) participants from a convenience sample of Early Childhood Education and Care Centers between September 2014 and March 2015. The 35 Early Childhood Education and Care Centers included in the study were in New South Wales (NSW) and the Australian Capital Territory (ACT), Australia, many being in areas of recognised disadvantage across urban and rural areas. The demographics of these jurisdictions are similar to those of Australia overall, with 2.9 and $2.8 \%$ of the NSW and ACT population respectively identifying as Aboriginal or Torres Strait Islander, as compared to $2.8 \%$ of the overall Australian population. The most common reported ancestry in NSW are Australian, English, Irish, Scottish, and Chinese, the same as Australia as a whole, whereas the ACT has fewer people of Chinese origin. Basic education levels are similar, with 15 and $18 \%$ of people in NSW and ACT, respectively, having completed high school, compared to $16 \%$ of the overall Australian population. Median household income is slightly higher in the ACT (\$1886), compared to NSW (\$1486) and Australia overall (\$1438); (Australian Bureau of Statistics, 2017).

All children $(N=1525)$ aged 3-5 years attending the Early Childhood Education and Care Centers (ECEC) in September 2014 were invited to participate through the distribution of a Participant Information Sheet from data collectors and ECEC staff. Parents completed written informed consent for themselves and their child, and children verbally assented to participate in the project prior to data collection. Children received gifts (e.g., drink bottles, balls) in appreciation for participating in the study. All thirteen data collectors involved in the project had a NSW Working With Children Check (a government mandated background check). Members of the project team trained data collectors in standard measurement procedures and provided them with manuals, checklists, and scripts to use during data collection. The University of Wollongong Human Research Ethics Committee (HE14/250) granted approval for this study.

\section{Measurements}

A wide range of data were collected for this project. Data used for the purpose of the analyses in this paper are described below. Two trained data collectors measured the height and weight of children following standardised protocols. For height measurements, data collectors used a Seca 217 portable stadiometer with the child standing upright without shoes. Data collectors took the measurements twice (to the nearest 
$0.1 \mathrm{~cm}$ ), and we used the average of the two measurements for analyses. If there was a difference of more than $0.5 \mathrm{~cm}$ between these two initial measurements, data collectors took a third measurement. The height used in the analyses was the average of the two closest measurements.

For weight measurements, data collectors used a Seca scale 874. Data collectors asked the child to remove any heavy clothing and shoes. Data collectors took the measurements twice (to the nearest $0.1 \mathrm{~kg}$ ) with the average of the two measurements used for analyses. If there was a difference of more than $0.5 \mathrm{~kg}$ between these two initial measurements, data collectors took a third measurement. As above, the weight used in the analyses was the average of the two closest measurements.

We calculated Body Mass Index (BMI; body mass $[\mathrm{kg}] / \mathrm{height}\left[\mathrm{m}^{2}\right]$ ), and then, based on the age and sex of the children, we classified participants into underweight, healthy weight, overweight, and obese categories using cut-points established by the International Obesity Task Force (IOTF; Cole \& Lobstein, 2012; Cole et al., 2000). Consistent with Garasky et al. (2009) for the purpose of the weight category and BMI analyses, we removed children categorised in the underweight range, due to the non-linear nature of BMI risk and potential impact of underweight status on child development.

\section{Parent Questionnaire}

Parents completed a questionnaire that collected information on demographics, key aspects of the HLE, and dietary intake information. Parents completed the 20-min questionnaire consisting of 77 questions either online or on paper, or a data collector administered it to them over the phone. Participants who completed the paper version returned their completed questionnaire to their ECEC center.

The questionnaire included basic questions about parents' demographic characteristics and socioeconomic factors, including income and parental education. Parents reported their family's total income before tax in the past year by choosing one of eleven income brackets (e.g. AU\$0-24,999, AU\$25,000-49,999). Parents reported their highest level of schooling by choosing one of eight options (e.g., no schooling/did not complete primary school, primary school or equivalent, year 10 or equivalent). Sixteen questions regarding HLE enquired about the presence and frequency of eight specific home-based activities that might provide learning opportunities for the child. The eight activities included were: reading to the child; visiting a library; teaching dance/sport or other physical activity; playing with letters; teaching the alphabet; teaching numbers/counting; teaching songs, poems or nursery rhymes; and painting/drawing (Melhuish et al., 2008). For each activity there was an initial question, such as 'Does anyone at home ever read to this child?' (answered as yes/no), and follow up question, such as 'If yes, how often does someone at home read to this child?'. For the follow up questions regarding frequency of the activity, there were set responses for parents to choose from, which differed depending on the activity. For the reading question, there were five response options: occasionally or less than once a week, once a week, several times a week, once a day, or more than once a day. For the library question, there were four possible responses: on special 
occasions, once a month, once a fortnight, or once a week. For all other questions, there were seven response options: occasionally or less than once a week, 1-2 days per week, 3 times per week, 4 times per week, 5 times per week 6 times per week, or 7 times per week or more. The responses were then scored from 0 (responding 'no' to the initial question) through to 4,5 , or 7 (depending on the frequency question for the particular activity). We then calculated a composite HLE index (possible range 0-51) using the sum of the scores from each frequency question.

The dietary intake component of the questionnaire consisted of seven questions; five questions collected information regarding intake of core food (vegetables, fruit, meat and meat alternatives, cereal foods, milk, yoghurt, and cheese or alternatives). Two other questions with multiple response options asked parents to report the frequency of their intake of energy-dense discretionary food intake (e.g., takeaway or fast food; sugary cereals; potato chips or other salty snacks; sweets; cakes, doughnuts, sweet cookies, or muffins; and sugary drinks). We modified these questions from the previously validated Eating and Physical Activity Questionnaire (Bennett et al., 2009) to include sugary cereals. In the original questionnaire some of the discretionary items referred to 'usual' intake and others referred to intake 'yesterday.' We made changes so that all discretionary items could be included succinctly in one question and we asked about 'usual' intake for all items. We also asked about the number of portions of all core food groups on a usual day, whereas the original questionnaire only asked about usual intake of vegetables.

We dichotomised core food intake responses into two categories for each of the individual core food groups (fruits; vegetables; meat and alternatives; bread and cereals; and milk, yoghurt, cheese or alternatives) according to whether participants met the Australian Dietary Guidelines or not (National Health \& Medical Research Council, 2013b); a yes response indicated they met the individual guideline for the core food group and a no response indicated they did not meet the individual guideline for the core food group. We then summed the number of guidelines that each participant met (out of a total of 5 if they met the guidelines for all five food groups). We derived a discretionary food score for each item of the discretionary food question using parent responses to a multi-item question on the frequency of consumption of takeaway or fast food; sugary cereals; potato chips or other salty snacks; sweets; cakes, doughnuts, sweet cookies, or muffins; and sugary drinks. Parents responded to these questions using the provided options of: never or rarely; 1-3 times/month; 1-2 times/week; 3-4 times/week; 5-6 times/week; once a day; or, 2 or more times/day. We scored each question response on a scale from 0 (rarely or never) to 6 ( 2 or more times/day). We then calculated a composite discretionary food score with the sum of the scores from each of the six items, with a possible score range from 0 to 36 .

\section{Statistical Analyses}

We conducted linear regression analyses to examine the associations between HLE index and BMI, HLE and discretionary food intake score, and HLE and sugary drink intake. We used ordinal logistic regression to examine associations between 
HLE index and the number of dietary guidelines met, and HLE and children's IOTF weight category. We conducted logistic regression to examine the association between HLE index and meeting the fruit and vegetable dietary guidelines. We used linear regression to examine the associations between discretionary food intake and specific elements of HLE (reading to the child; visiting a library; teaching dance/sport or other physical activity; playing with letters; teaching the alphabet; teaching numbers/counting; teaching songs, poems or nursery rhymes; and painting/drawing). We conducted both unadjusted and adjusted analyses. Due to prior research demonstrating relationships between childhood obesity and income (Wake et al., 2007), we adjusted the analyses to include the family's total income. We also adjusted all analyses for participating parents' highest level of schooling, because previous research has demonstrated a relationship between childhood obesity and parent educational attainment (Lakshman et al., 2013; Wake et al., 2007). We also conducted additional stratified analyses by total family income (lower $<$ AU\$50,000 and higher $\geq$ AU\$50,000-relating approximately to the poverty line), which we adjusted for parent's highest level of schooling. All analyses were performed with Stata version 13.1 (StatCorp, Texas) using a significance level of $p<0.05$.

\section{Results}

\section{Participants}

A total of 786 children were recruited in the Early Start Baseline Project and participated in the center-based data collection (including height and weight). While all parents of these children were offered the opportunity to complete a questionnaire, we received questionnaires for only 303 of the children. These children were from 32 centers and there were an average of $9.5(S D=6.2)$ children from each center, ranging from 2 to 27 children. Table 1 displays our sample's descriptive statistics, stratified by total family income. The mean age of child participants in this sample was 4.5 years $(S D=0.7)$ and ranged from 3.0 to 6.0 and the mean age of parent participants was 35 years $(S D=6.4)$, ranging from 21 to 62 . One-third of participants $(30 \%)$ had a total annual family income of less than $\$ 50,000$ per year, suggesting that many of these families were living below the poverty level (defined as a total household income of $\$ 46,679$ for a couple with two children in Australia in 2014; (Australian Council of Social Service, 2016). Around one-third of participating parents ( $96 \%$ of whom were mothers) were not employed, as is the case in the overall Australian adult population (Baxter, 2013), and 33\% had completed a university degree (also similar to the general Australian population; Australian Bureau of Statistics, 2018). 
Table 1 Demographic characteristics of participants in the Early Start Baseline Project

\begin{tabular}{|c|c|c|c|}
\hline Variable & $\begin{array}{l}\text { Below poverty line } \\
(<\$ 50,000) n(\%)\end{array}$ & $\begin{array}{l}\text { Above poverty line } \\
(\geq \$ 50,000) n(\%)\end{array}$ & Total $n(\%)$ \\
\hline \multicolumn{4}{|l|}{ Sex of child $(n=277)$} \\
\hline Male & $48(53 \%)$ & $101(54 \%)$ & $149(54 \%)$ \\
\hline Female & $43(47 \%)$ & $85(46 \%)$ & $128(46 \%)$ \\
\hline Age of child $(n=303)$ mean $(S D)$ & $4.44(0.74)$ & $4.55(0.73)$ & $4.50(0.74)$ \\
\hline \multicolumn{4}{|l|}{ Sex of parent $(n=277)$} \\
\hline Male & $4(4 \%)$ & $8(4 \%)$ & $12(4 \%)$ \\
\hline Female & $87(96 \%)$ & $178(96 \%)$ & $265(96 \%)$ \\
\hline Age of parent $(n=292)$ mean $(S D)$ & $34.38(7.14)$ & $35.47(5.26)$ & $35.08(6.41)$ \\
\hline \multicolumn{4}{|l|}{ Marital Status $(n=276)$} \\
\hline Never married, single parent & $25(28 \%)$ & $6(3 \%)$ & $31(11 \%)$ \\
\hline Never married, live with partner & $15(17 \%)$ & $28(15 \%)$ & $43(16 \%)$ \\
\hline Married, live with spouse & $26(29 \%)$ & $145(79 \%)$ & $171(62 \%)$ \\
\hline Separated/divorced & $24(26 \%)$ & $5(3 \%)$ & $29(11 \%)$ \\
\hline Widowed & $1(1 \%)$ & $1(<1 \%)$ & $2(<1 \%)$ \\
\hline \multicolumn{4}{|l|}{ Parent education $(n=246)^{\mathrm{a}}$} \\
\hline Primary school or equivalent & $5(6 \%)$ & $1(<1 \%)$ & $6(2 \%)$ \\
\hline Year 10 or equivalent & $31(36 \%)$ & $22(12 \%)$ & $53(22 \%)$ \\
\hline Year 12 or equivalent & $15(17 \%)$ & $35(19 \%)$ & $50(21 \%)$ \\
\hline $\begin{array}{l}\text { Trade/apprenticeship/certificate/ } \\
\text { diploma }\end{array}$ & $26(30 \%)$ & $53(29 \%)$ & $79(32 \%)$ \\
\hline University degree & $9(10 \%)$ & $49(26 \%)$ & $58(24 \%)$ \\
\hline \multicolumn{4}{|l|}{ Employment $(n=277)$} \\
\hline Employed full-time & $9(10 \%)$ & $36(19 \%)$ & $45(16 \%)$ \\
\hline Employed part-time & $16(18 \%)$ & $92(50 \%)$ & $108(39 \%)$ \\
\hline Self-employed & $6(7 \%)$ & $24(13 \%)$ & $30(11 \%)$ \\
\hline Not employed & $55(60 \%)$ & $24(13 \%)$ & $79(29 \%)$ \\
\hline Other & $5(6 \%)$ & $10(5 \%)$ & $15(5 \%)$ \\
\hline \multicolumn{4}{|c|}{ Child weight status (IOTF definition) $(n=268)$} \\
\hline Underweight & $4(5 \%)$ & $6(<1 \%)$ & $10(4 \%)$ \\
\hline Healthy weight & $64(74 \%)$ & $149(82 \%)$ & $213(79 \%)$ \\
\hline Overweight & $10(12 \%)$ & $22(12 \%)$ & $32(12 \%)$ \\
\hline Obese & $9(10 \%)$ & $4(2 \%)$ & $13(5 \%)$ \\
\hline
\end{tabular}

${ }^{a}$ Original response categories for parent education were collapsed due to a low number of responses in some categories

\section{Child Weight Status}

As displayed in Table 1, according to the IOTF cut-offs, most child participants (79\%) were in the healthy weight range according to the IOTF cut-offs, while $17 \%$ were in the overweight or in the obese range, comparable to the Australian population (Australian Bureau of Statistics, 2018). 


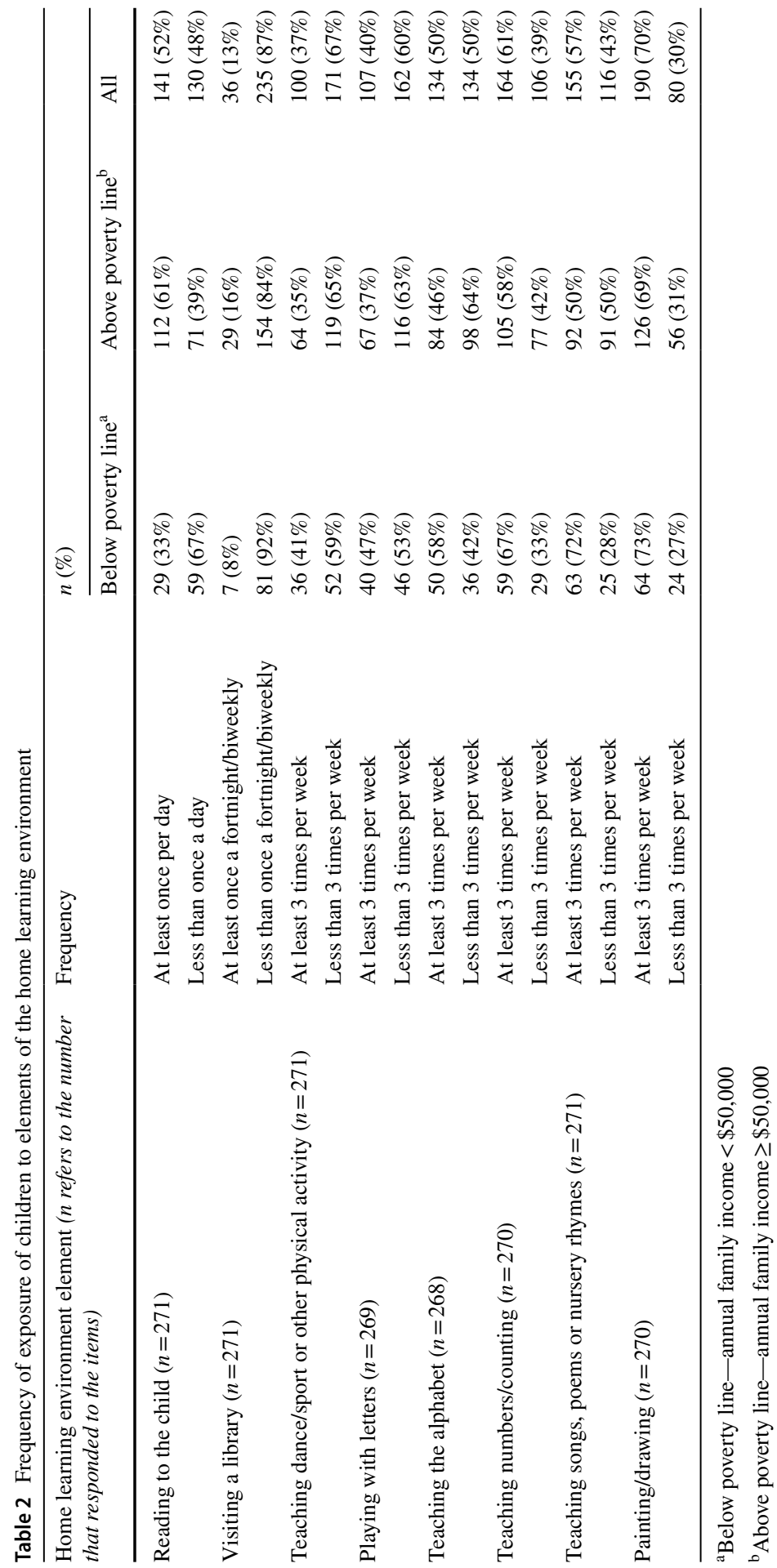




\section{The Home Learning Environment}

The overall mean HLE index was 24.5 ( $S D=9.7$; Range 4-50). Table 2 displays the frequency of participation in specific elements of HLE stratified by income.

\section{Home Learning Environment and Weight Status}

Table 3 displays the results of the regression analyses on the effect of HLE on weight status. We found no significant relationship between HLE index and BMI after adjusting for parent education and total household income, nor a significant relationship when analyses were stratified by income. Similarly, we found no significant relationship between HLE environment and IOTF weight category after adjusting for parent education and total household income, nor did we find a significant relationship when we stratified by income.

\section{The Home Learning Environment and Dietary Intake}

As displayed in Table 3, there was an inverse relationship between HLE index and discretionary food intake score (meaning the higher the frequency of intake of discretionary foods, the lower the HLE index and vice versa). When stratified by income, this relationship existed only for those from lower-income families after adjusting for parent education. When we considered sugary drinks intake separately, we also found an inverse relationship with HLE index (the higher the intake of sugary drinks, the lower the HLE index and vice versa). However, again, when stratified by income, we only found this significant relationship for lower-income families after adjusting for education. We found no significant relationship between the HLE and the number of dietary guidelines met, or meeting the fruit and vegetable intake guidelines.

Table 4 displays the relationships between discretionary food intake and specific elements of the HLE. We found a significant inverse relationship between discretionary food intake and frequency of reading to the child, which was significant across both lower- and higher-income levels after adjusting for parent education level. There was a significant inverse relationship between discretionary food intake and teaching the alphabet, but when stratified by income, the relationship was only significant for higher-income families. We also found several significant inverse relationships between discretionary food intake and specific elements of the HLE which were only significant for children from lower-income families (after adjustment for parent education level), including: visiting the library, teaching numbers or counting, and teaching songs, poems or nursery rhymes. These inverse relationships indicate that the higher the frequency of discretionary food intake, the lower the frequency of these HLE activities and vice versa. 


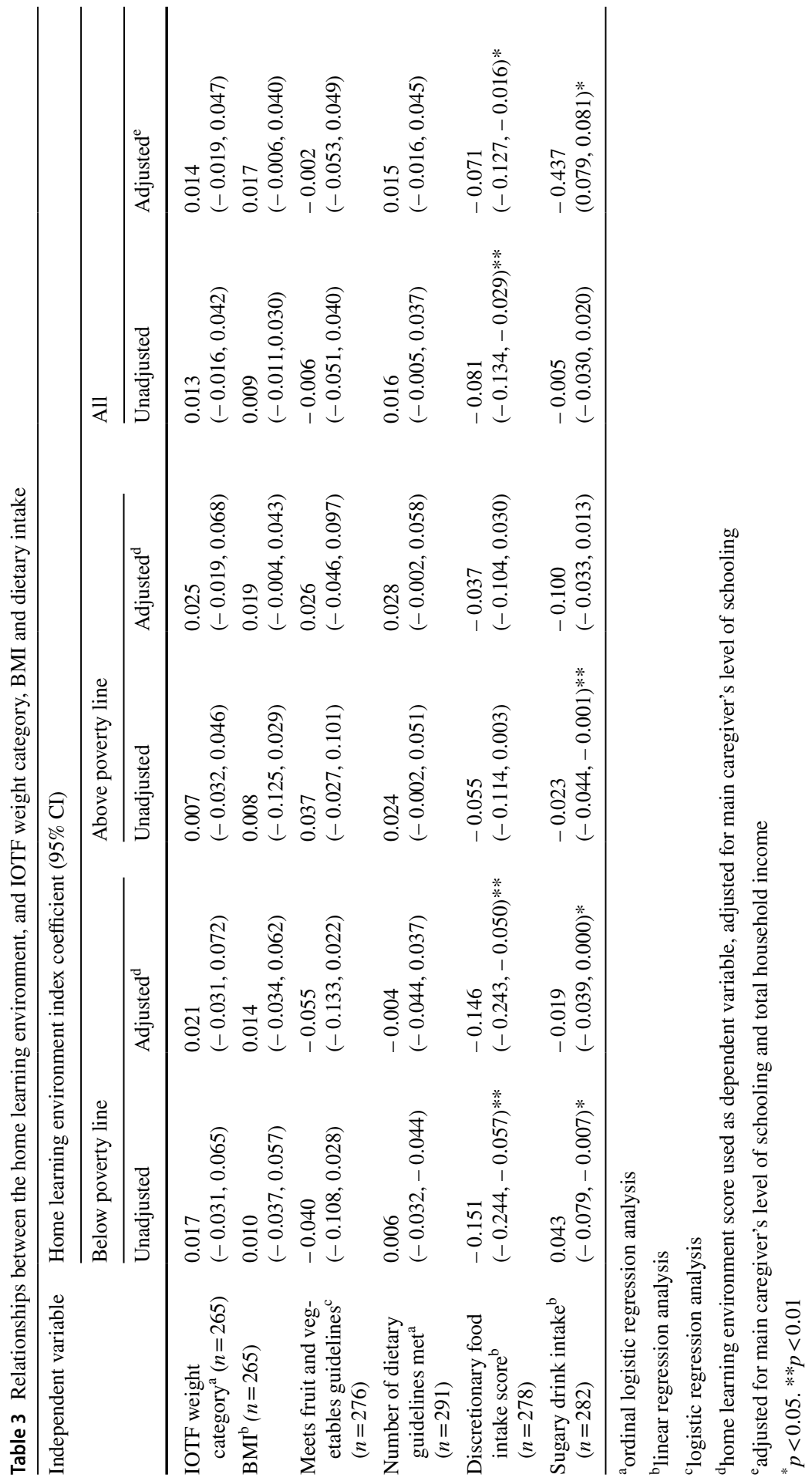




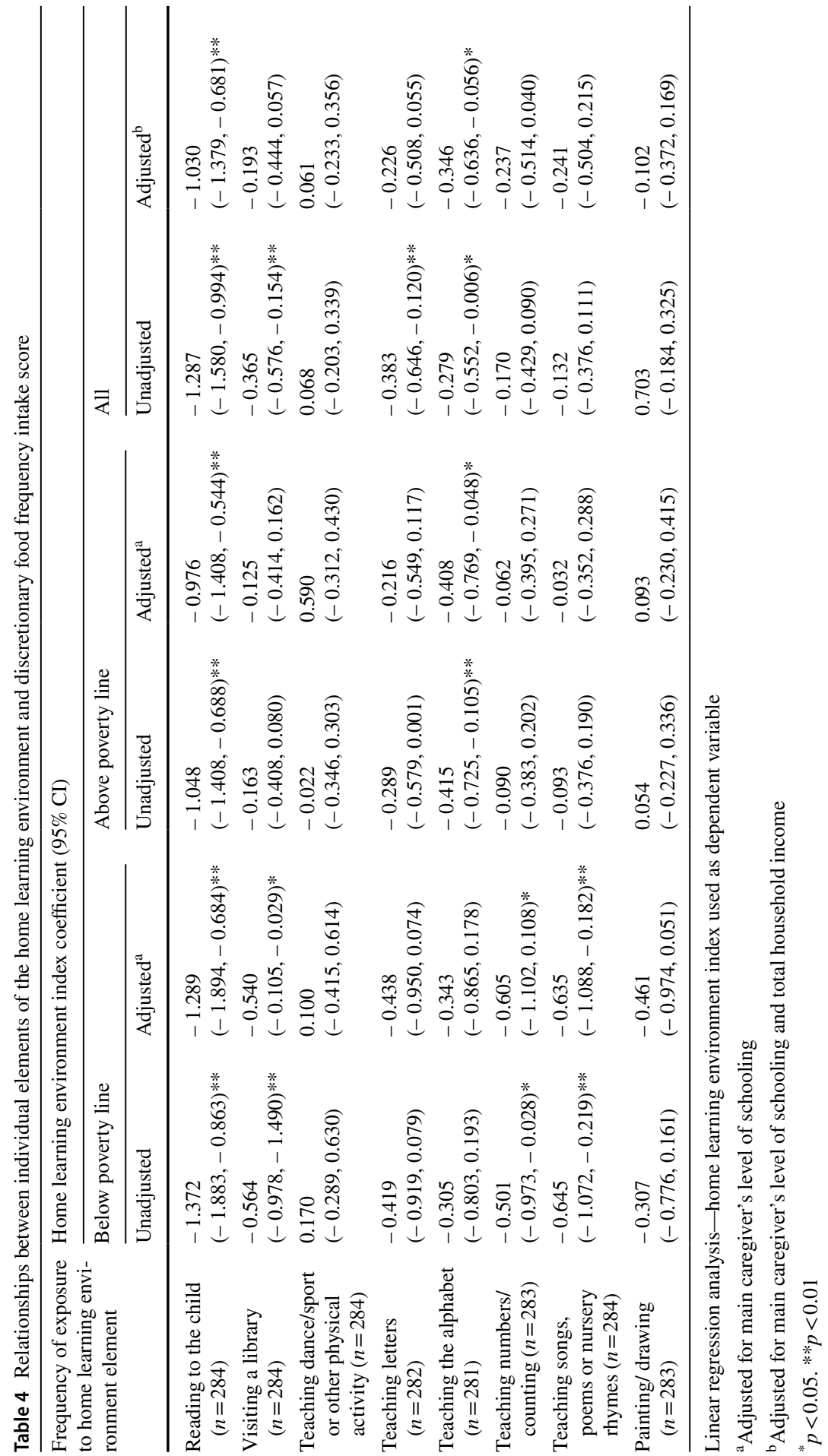




\section{Discussion}

In this study, we examined the relationships between aspects of HLE and child weight status, and between HLE and child dietary intake, using a sample of children from disadvantaged populations in NSW and ACT, Australia. We hypothesised that engagement in intellectually stimulating activities in the home environment, measured by an overall composite HLE index, would be inversely associated with BMI and overweight/obesity, positively associated with healthy eating behaviors, and inversely associated with the frequency of consumption of energy-dense discretionary foods. The results of the study did not support the hypothesis that the HLE would be inversely associated with BMI and overweight/obesity. We did however find a significant inverse association between the HLE and frequency of discretionary food consumption and sugary drink consumption. We found no significant relationship either between the HLE and number of dietary guidelines met, or meeting fruit and vegetable guidelines. When considering the specific elements of the HLE, we found an inverse association between discretionary food intake and the following elements: reading to the child in both the lower- and higher-income sub-groups; and teaching the alphabet for those in the higher income sub-group. In lower-income families only, we found an inverse association between discretionary food intake and visiting a library, teaching numbers or counting, and teaching songs, poems or nursery rhymes. There has been limited research in this field and most studies conducted that have explored HLE relationships have assessed only BMI/weight status or food intake, not both.

Similar to our study, Pieper et al. (2011) found associations between food intake and both HLE index and reading. However, significant aspects of food intake were different between the two studies, insofar as our study found an inverse association between HLE index and discretionary food intake, whereas Pieper et al. (2011) found no associations between HLE and similar factors such as fast food intake and soft drink intake. Further, the Pieper study found associations between HLE and both fruit and vegetable intake, whereas we found no such associations. There were several differences between the two studies, so comparisons should be made cautiously. Firstly, the Pieper study included only children from lower-income families, whereas while we conducted our study within lower-income communities, we included children from both lower- and higher-income families. The HLE tool used by Pieper and colleagues assessed some items that were similar to the tool we used (frequency of teaching letters, words or numbers, visiting a library, and playing music or singing songs). However, our tool also assessed teaching dance, sport or physical activities, and painting/drawing. The tool we used also included reading in its combined index and we also considered it separately, whereas the tool used by Pieper considered this element only separately. The dietary intake tools used in the studies also had some similarities and differences. While both tools assessed fruit and vegetable intake, the tool used by Pieper assessed only frequency of soft drink and fast food intake, while ours assessed frequency of discretionary food intake through a score comprising multiple items (takeaway or fast food; sugary cereals; potato chips or other salty snacks; sweets; cakes, doughnuts, sweet cookies, or muffins; and sugary drinks). 
In regard to HLE and weight status, a cross-sectional study by Garasky et al. (2009) found lack of cognitive stimulation was associated with overweight/obesity. Although there is a lack of longitudinal studies in this area, most have reported a significant inverse relationship between baseline cognitive score (Strauss et al., 1999), cognitive elements (Avula et al., 2011), or HLE score (Lumeng et al., 2005) and weight status at follow-up, with the exception of the most recent study by den Bosch et al. (2017), who found no relationship. Den Bosch and colleagues did, however, report that a cognitively stimulating home environment was associated with a lower level of junk food intake at follow-up. While some of these studies have included children in the preschool age-group (den Bosch et al., 2017; Strauss et al., 1999), others have been conducted with older children (Avula et al., 2011; Lumeng et al., 2005), and some have focussed primarily on children from lower-income families (den Bosch et al., 2017). Despite the emphasis on income levels, the effect of elements within HLE on later weight status may not be due to socioeconomic status as studies with lower- and higher-income families have demonstrated (Avula et al., 2011; Strauss \& Knight, 1999). Although we did not observe a significant relationship between HLE and weight status in children from lower- or higher-income families, we did find a significant relationship between reading to the child and discretionary food intake in children from both lower- and higher-income families, which also suggests that this relationship is not just attributable to income level. There were, however, some relationships observed which were significant only in children from lower-income families. Although the reason for these differences is unclear, previous research has indicated that there is greater availability of discretionary foods in lower-income households (Ding et al., 2012; Ranjit et al., 2015). Therefore, HLE may play a more protective role in lower-income households, whereby engagement in learning activities may limit exposure to these foods. Engaging in learning activities may displace other activities, such as TV viewing which is associated with excess consumption of discretionary foods (Zhang et al., 2016).

Our sample was broadly representative of the Australian population is regard to the proportion of children who were in the overweight and obese categories. Our sample of 3- to 6-year-old children consisted of $17 \%$ in the overweight and obese ranges combined, comparable to national statistics of $15 \%$ in children aged 2-3 years, and 17\% in children aged 5-7 years (Australian Bureau of Statistics, 2018). The fact that we found no significant associations between overweight/ obesity and aspects of HLE may be due to the cross-sectional design of the study and the young age of participants compared to other studies. It is plausible that the observed unhealthy behaviors had not yet made an impact on the weight status of these children. Given that there were significant relationships between elements of HLE and discretionary food and drink intake, it is likely that relationships may develop between HLE and weight status at a future point in time. Other possible reasons why we found no significant relationship between HLE and weight status may be the modest size of our study sample, which was considerably smaller than some other studies, and our use of slightly different measures to assess HLE.

It appears that the home environment has a critical role to play in the development of healthy behaviors, which is likely due to a complex interplay of factors. While we focused on the impact of HLE on child weight status and dietary intake, 
it is probable that other factors within the home environment play a key role in this relationship. As previous studies have indicated, in addition to HLE/cognitive stimulation, other factors such as parental warmth, setting screen-time limits and sleep schedules (Avula et al., 2011), family stress and emotional support (Garasky et al., 2009), have all been associated with overweight and/or dietary intake. Therefore, there is likely to be an interplay of various factors contributing to these associations. A home environment where positive parenting practices and strategies are implemented, where parents demonstrate warmth and spend time with their child can provide an opportunity for children to be emotionally secure, self-regulate behavior, and maybe, less likely to exhibit emotional eating practices (Avula et al., 2011). Boredom and time spent watching TV have been associated with obesity through displacement of sleep and exposure to unhealthy food advertising (Jochem, Schmid, \& Leitzman, 2018; Zhang et al., 2016); both circumstances can possibly be alleviated when parents spend time with their children reading and participating in other cognitively-stimulating activities.

Despite being conducted prior to the COVID-19 pandemic, our study has current relevance. Worldwide, the pandemic has led to repeated lockdowns and to a reduction in the availability of care outside the home. As a direct result, the home learning environment has become even more important. In alignment with the results of this study, the home learning environment is now more than ever a critical environment for children's health and wellbeing. Regardless of the pandemic, it continues to be important that the quality of the home learning environment be optimised to further improve children's outcomes.

Our study has some limitations. Given its cross-sectional nature, we cannot draw conclusions regarding causality, nor were we able to determine how these outcomes change over time. As variables were assessed at just one point in time, our results may be unstable as there can be rapid changes in height, weight, and lifestyle habits in this age group. The response rate to our parent questionnaire was quite modest (39\%). Although we used previously validated parent-reported questionnaires, some were modified, and as with many other similar studies, it is possible that parent's responses may have been impacted by a social desirability bias. Therefore they may have over-reported positive aspects of HLE (Chun-Li et al., 2011) and failed to fully report dietary intake (Gemming, Jiang, Swinburn, Utter, \& Mhurchu et al., 2014; Poslusna, Ruprich, De Vries, Jakubikova, \& Van't Veer, 2009).

Although it is difficult to compare our study with the results of previous research, our findings make an important contribution to the knowledge base regarding the critical importance of the home environment for developing healthy behaviors for children's wellbeing. There are a multitude of variables within the home environment that potentially influence dietary intake and child weight status, and those relationships are likely due to an interplay of many factors. Our study also adds weight to previous research that has demonstrated that some HLE relationships exist across all income groups, indicating that they are not just a consequence of socioeconomic status. While this area of research clearly requires further study, the cumulative findings from our study, in conjunction with those we reviewed, suggest that improving HLE may be of benefit in promoting healthy eating behaviors and/or healthy weight 
in children. In addition to the home learning environment and dietary intake variables, we recommend that future studies investigate a combination of interrelated factors such as availability of healthy foods, local food environment, food security, availability of physical activity resources, stress, family dynamics, living standards, parent warmth, limit setting, and ethnicity and culture. Furthermore, longitudinal studies would greatly assist in determining causality and the effects changes in these factors over time might have on the wellbeing of children.

\section{Conclusion}

Further research is needed on relationships between HLE/cognitive stimulation and overweight/obesity and dietary intake in children, as well as how broader home environment factors may influence these relationships. Our study provides interesting insights into relationships between HLE and dietary intake in children from both lower- and higher-income families and makes an important contribution to the literature in this area. The findings of this and prior studies should be of interest to early childhood clinicians and educators and may inform the advice and encouragement they provide to parents regarding the importance of engaging in home learning activities. Further, there may be potential in exploring intervention approaches to improve HLE as an indirect strategy to improve eating behaviors in children. We recommend that future studies investigate strategies to successfully improve parent engagement in home learning activities with their young children.

Acknowledgements The authors would like to thank the Faculty of Social Sciences, University of Wollongong who funded the study, Project Managers Dr. Eva Craig, Dr. Franca Mackie and Fay Gowers, and the data collectors who assisted with the study. They would also like to thank Penny Cross for her assistance with data management, Professor Marijka Batterham for her statistical advice, Professor Edward Melhuish for his advice on the use of the Home Learning Environment index, as well as the Early Childhood Education and Care services and all the parents and children who participated in the study.

Funding This study was funded by the Faculty of Social Sciences, University of Wollongong.

\section{Declarations}

Conflict of interest The authors declare no conflicts of interest.

Ethical approval All procedures performed were in accordance with the ethical standards of the University of Wollongong Human Research Ethics Committee (HE14/250) and with the 1964 Helsinki declaration and its later amendments or comparable ethical standards.

Informed consent We obtained informed consent from all individual participants included in this study.

\section{References}

Australian Council of Social Service. (2016). Poverty in Australia 2016. Sydney, Australia: Australian Council of Social Service 
Australian Bureau of Statistics. (2017). 2016 Census QuickStats. Canberra: Australian Bureau of Statistics.

Australian Bureau of Statistics. (2018). National Health Survey: First Results. ABS cat. no. 4364.0.55.001. Canberra: Australian Bureau of Statistics.

Australian Bureau of Statistics. (2018). Education and Work, Australia, May 2018. ABS cat. no 6227.0. Canberra: Australian Bureau of Statistics.

Avula, R., Gonzalez, W., Shapiro, C. J., Fram, M. S., Beets, M. W., Jones, S. J., Blake, C. E., \& Frongillo, E. A. (2011). Positive parenting practices associated with subsequent childhood weight change. Journal of Primary Prevention, 32, 271-281. https://doi.org/10.1007/s10935-011-0256-6

Baxter, J. (2013). Parents working out work (Australian Family Trends No 1). Melbourne: Australian Institute of Family Studies.

Bennett, C. A., de Silva-Sanigorski, A. M., Nichols, M., Bell, A. C., \& Swinburn, B. A. (2009). Assessing the intake of obesity-related foods and beverages in young children: Comparison of a simple population survey with $24 \mathrm{hr}$-recall. International Journal of Behavioral Nutrition and Physical Activity, 6, 71. https://doi.org/10.1186/1479-5868-6-71

Christoffel, K. K., \& Forsyth, B. W. C. (1989). Mirror image of environmental deprivation: Severe childhood obesity of psychosocial origin. Child Abuse and Neglect, 13(2), 249-256.

Chun-Li, W., Chiang, J. T. L., \& Bradley, R. H. (2011). Adaptation and validation of the HOME-SF as a caregiver-report home environment measure for use in the Taiwan Birth Cohort Study (TBCS). Early Child Development and Care, 181(7), 949-965. https://doi.org/10.1080/03004430.2010. 504881

Cole, T. J., Bellizi, M. C., Flegal, K. M., \& Dietz, W. H. (2000). Establishing a standard definition for child overweight and obesity worldwide: International survey. BMJ, 320(7244), 1240-1243. https:// doi.org/10.1136/bmj.320.7244.1240

Cole, T. J., \& Lobstein, T. (2012). Extended international (IOTF) body mass index cut-offs for thinness, overweight and obesity. Pediatric Obesity, 7(4), 284-294. https://doi.org/10.1111/j.2047-6310. 2012.00064.x

den Bosch, S. O., \& Duch, H. (2017). The role of cognitive stimulation at home in low-income preschoolers' nutrition, physical activity and body mass index. BMC Pediatrics, 17, 178. https://doi.org/10. 1186/s12887-017-0918-5

Ding, D., Sallis, J. F., Norman, G. J., Saelens, B. E., Harris, S. K., Kerr, J., Rosenberg, D., Durant, N., \& Glanz, K. (2012). Community food environment, home food environment, and fruit and vegetable intake of children and adolescents. Journal of Nutrition Education and Behavior, 44(6), 634-638. https://doi.org/10.1016/j.jneb.2010.07.003

Garasky, S., Steward, S. D., Gundersen, C., Lohman, B. J., \& Eisenmann, J. C. (2009). Family stressors and child obesity. Social Science Research, 38(4), 755-766.

Gemming, L., Jiang, Y., Swinburn, B., Utter, J., \& Mhurchu, C. N. (2014). Under-reporting remains a key limitation of self-reported dietary intake: An analysis of the 2008/09 New Zealand Adult Nutrition Survey. European Journal of Clinical Nutrition, 68, 259-264. https://doi.org/10.1038/ejcn.2013.242

Jochem, C., Schmid, D., \& Leitzmann, M. F. (2018). Sedentary behaviour and adiposity. In C. Jochem \& D. Schmid (Eds.), MF Leitzmann. New York: Sedentary Behaviour Epidemiology. Springer International Publishing.

Johnson, R., Welk, G., St-Maurice, P., \& Ihmels, M. (2012). Parenting styles and home obesogenic environments. International Journal of Environmental Research and Public Health, 9(4), 1411-26. https://doi.org/10.3390/ijerph9041411

Lakshman, R., Zhang, J., Zhang, J., Koch, F. S., Marcus, C., Ludvigsson, J., Ong, K. K., \& Sobko, T. (2013). Higher maternal education is associated with favourable growth of young children in different countries. Journal of Epidemiology and Community Health, 67(7), 595- 602. https://doi.org/10. 1136/jech-2012-202021

Lau, E. Y., Barr-Anderson, D. J., Dowda, M., Forthofer, M., Saunders, R. P., \& Pate, R. R. (2015). Associations between home environment and after-school physical activity and sedentary time among 6th grade children. Pediatric Exercise Science, 27(2), 226-233. https://doi.org/10.1123/pes.2014-0061

Lissau-Lund-Sorensen, I., \& Sorenson, T. I. (1992). Prospective study of the influence of social factors in childhood on the risk of overweight in young adulthood. International Journal of Obesity, 16(3), $169-175$.

Lissau, I., \& Sorensen, T. I. (1994). Parental neglect during childhood and increased risk of obesity in young adulthood. Lancet, 343(8893), 324-327. https://doi.org/10.1016/s0140-6736(94)91163-0 
Lumeng, J. C., Gannon, K., Appugliese, D., Cabral, H. J., \& Zuckerman, B. (2005). Preschool child care and risk of overweight in 6- to 12-year-old children. International Journal of Obesity, 29(1), 60-66. https://doi.org/10.1038/sj.ijo.0802848

Melhuish, E., Sylva, K., Sammons, P., Siraj-Blatchford, I., Taggart, B., \& Phan, M. (2008). Effects of the home learning environment and preschool center experience upon literacy and numeracy development in early primary school. Journal of Social Issues, 64(1), 95-114. https://doi.org/10.1111/j. 1540-4560.2008.00550.x

Natale, R. A., Messiah, S. E., Asfour, L., Uhlhorn, S. B., Delamater, A., \& Arheart, K. L. (2014). Role modeling as an early childhood obesity prevention strategy: effect of parents and teachers on preschool children's healthy lifestyle habits. Journal of Developmental and Behavioral Pediatrics, 35(6), 378-387. https://doi.org/10.1097/DBP.0000000000000074

National Health and Medical Research Council. (2013b). Australian Dietary Guidelines. Canberra, Australia:National Health and Medical Research Council

National Health and Medical Research Council. (2013a). Clinical Practice Guidelines for the Management of Overweight and Obesity in Adults, Adolescents and Children in Australia. Canberra, Australia: National Health and Medical Research Council

Ng, M., Fleming, T., Robinson, M., Thomson, B., Graetz, N., Margono, C., \& Gakidou, E. (2014). Global, regional, and national prevalence of overweight and obesity in children and adults during 1980 - 2013: A systematic analysis for the global burden of disease Study. Lancet, 384, 766-781. https://doi.org/10.1016/S0140-6736(14)60460-8

Niemeier, B. S., Hektner, J. M., \& Enger, K. B. (2012). Parent participation in weight-related health interventions for children and adolescents: A systematic review and meta-analysis. Preventive Medicine, 55(1), 3-13. https://doi.org/10.1016/j.ypmed.2012.04.021

Pieper, J. R., \& Whaley, S. E. (2011). Healthy eating behaviors and the cognitive environment are positively associated in low-income households with young children. Appetite, 57(1), 59-64. https://doi. org/10.1016/j.appet.2011.03.016

Poslusna, K., Ruprich, J., De Vries, J. H., Jakubikova, M., \& Van't Veer, P. (2009). Misreporting of energy and micronutrient intake estimated by food records and 24 hour recalls, control and adjustment methods in practice. . British Journal of Nutrition, 101(2), S73-85. https://doi.org/10.1017/ S0007114509990602

Ranjit, N., Wilkinson, A. V., Lytle, L. M., Evans, A. U., Saxton, D., \& Hoelscher, D. M. (2015). Socioeconomic inequalities in children's diet: the role of the home food environment. International Journal of Behavioral Nutrition and Physical Activity, 12(1), S4. https://doi.org/10.1186/ 1479-5868-12-S1-S4

Rosenkranz, R. R., \& Dzewaltowski, D. A. (2008). Model of the home food environment pertaining to childhood obesity. Nutrition Reviews, 66(3), 123-140. https://doi.org/10.1111/j.1753-4887.2008. 00017.x

Sokol, R. L., Qin, B., \& Poti, J. M. (2017). Parenting styles and body mass index: a systematic review of prospective studies among children. Obesity Reviews, 18(3), 281-292. https://doi.org/10.1111/obr. 12497

Strauss, R. S., \& Knight, J. (1999). Influence of the home environment on the development of obesity in children. Pediatrics, 103(6), e85. https://doi.org/10.1542/peds.103.6.e85

Vereecken, C., Haerens, L., De Bourdeaudhuij, I., \& Maes, L. (2010). The relationship between children's home food environment and dietary patterns in childhood and adolescence. Public Health Nutrition, 13, 1729-1735. https://doi.org/10.1017/S1368980010002296

Wake, M., Hardy, P., Canterford, L., Sawyer, M., \& Caarlin, J. B. (2007). Overweight, obesity and girth of Australian pre-schoolers: Prevalence and socio-economic correlates. International Journal of Obesity, 31(7), 1044-1051. https://doi.org/10.1038/sj.ijo.0803503

World Health Organization. (2012) Population-Based Approaches to Childhood Obesity Prevention. Geneva, Switzerland: World Health Organization

Yavuz, H. M., van Ijzendoorn, M. H., Mesman, J., \& van der Veek, S. (2015). Interventions aimed at reducing obesity in early childhood: A meta-analysis of programs that involve parents. Journal of Child Psychology and Psychiatry, 56(6), 677-692. https://doi.org/10.1111/jcpp.12330

Zhang, G., Wu, L., Zhou, L., Lu, W., \& Mao, C. (2016). Television watching and risk of childhood obesity: A meta-analysis. European Journal of Public Health, 26(1), 13-18. https://doi.org/10.1093/ eurpub/ckv213 
Publisher's Note Springer Nature remains neutral with regard to jurisdictional claims in published maps and institutional affiliations.

\section{Authors and Affiliations}

\section{Megan L. Hammersley ${ }^{1}\left[\right.$ - Rachel A Jones ${ }^{1} \cdot$ Anthony D Okely $^{1}$}

$\bowtie$ Megan L. Hammersley

mhammers@uow.edu.au

1 Early Start, Faculty of the Arts, Social Sciences and Humanities, University of Wollongong,

Northfields Ave, Wollongong, NSW 2522, Australia 